\title{
The Definiteness and Indefiniteness in the Theme
}

\author{
Gunel Eyvazli ${ }^{1}$ \\ ${ }^{1}$ Azerbaijan University of Languages, Baku, Azerbaijan \\ Correspondence: Gunel Eyvazli, Department of II Foreign Language, Azerbaijan University of Languages, Baku, \\ Azerbaijan. E-mail: s.gurbanova@yahoo.com
}

\author{
Received: May 29, 2015 Accepted: June 28, 2015 Online Published: July 30, 2015 \\ doi:10.5539/ijel.v5n4p144 URL: http://dx.doi.org/10.5539/ijel.v5n4p144
}

\begin{abstract}
The article describes the (in)definitenessin the Theme. Usually a themeisthe subject, and (in)definiteness is employed as an independent information structure used by speakers or writers to express their intention. Having investigated a lot of linguistic references, the author gives the explanation of them. The definiteness means the status of the information. Basing on different linguists the author defines the definite articles, the demonstrative pronouns, the possessive adjectives (pronouns), personal pronouns, proper nouns as the indicators of the definiteness. The indefinite articles, the indefinite pronouns are investigated as the indefinite indicators. The author gives some examples for proving her investigation. She gives the three methods of T.Givon in her research and relies on his (T.Givon's) methods while experimenting. The author comes to the conclusion that the stated grammatical themes are observed in the definiteness of the Theme more than in the Rheme.
\end{abstract}

Keywords: text, discourse, definiteness, indefiniteness, theme, rheme, information, new, known, unknown, article, pronoun

\section{Introduction}

Each sentence contains the predicate. The subject is the carrier of the subjective idea, and the subject can be repeated by the help of the predicative and by the help of personal endings in the nominal predicate that is stated at the end of the sentence. The stated predicative closes the system (sentence system). The process of the closing causes the formation of the sentence. Basing on this idea it means that a sentence is formed "when the personal ending directs the attention of the repetition to the first element-to the subjective idea of a lexical phrase" and as a result the boundaries of a sentence is formed. A.Abdullayev claims that historically each sentence had its predicative, gradually earlier words get the character of predicative (weak predicative) and finally, the predicative strengthens in the predicate of the sentence and the monopredicative sentences appear.

\section{Approaches to the Predicative}

There are other approaches to the predicative of the sentences. The predicative can be explained according to the relation of two elements - definiteness and indefiniteness. According to this approach predicative can be analyzedin three variants: 1) predicative - it is the relation of a subject and a predicate (logical aspect); 2) it is the relation of the theme and the rheme (communicative aspect);3) it is the relation of the subject and the predicate (grammatical aspect).

There are not any kind of sentences that do not carry the components of definiteness and indefiniteness. All sentences have the character of the idea of the thought, but the idea of the thought is not always expressed by words. It can be understood in the semantics of a sentence. The main carrier of the predicative is the predicate. That is why sometimes the predicative and the predicate can be confused. The predicative has its grammatical means- the form of the verb, the time of the verb, personal affixes, particles, intonation and so on. So, a sentence is the central and main unit of the syntax. It has specific structural features and semantic signs. It should be noted that the stated signs are not temporal ones; they are permanent character signs of sentences. A sentence has a lot of importance in a language. It carries the phonetic system, vocabulary and grammatical structure. The sentence can include all branches of linguistics - phonetics, orphograhy, lexicology, semasiology, fraseology, onomalogy, morphology, morphonology, syntax, stylistics etc.

That is why we can state that a sentence is the result of language facts, various changings etc. All of these are used for forming a sentence. The words that form the sentence are related with each other according to the meaning and grammar. The "nonsence words" can not form a sentence. All words that are used to form the 
sentence have semantic meanings. There are two kinds of relation in every sentence. 1) semantic inside relation; 2) grammatical relation. These two relations can act at the same time.

The words that form the sentence carry the theme and the rheme. M.A.K.Halliday states that the Theme is the beginning point of a speaker based in the idea of being connection with the unmarked of the Theme and the Known. For checking this claim it is necessary to compare the definiteness and indefiniteness in the space of the Theme and the Rheme relatively (Halliday, 1967).

The definiteness means to identify concretely what is meant. E.Prince thinks that the definiteness can be looked through as information status, or in the line of the conception of linguistic forms. Basing on E.Prince we can consider the following as the signs of definiteness and indefiniteness (Prince, 1992):

\section{Definiteness:}

The definite article

The demonstrative articles

The possessive adjectives (pronouns)

Personal pronouns

Proper nouns

\section{Indefiniteness:}

The indefinite article

The indefinite modifiers

We should like to draw your attention to the fact that the use of the zero article is not mentioned in the stated groups. No number is shown about the usage frequency of the zero article. For discussing the problem of definiteness and indefiniteness in the theme we need to look through the connection between the definiteness and the discourse. First of all, we need to explain the thought of the meaning of the definiteness. There are a plenty of linguistic sources dealing with the mentioned problem including the typology of a language and discourse in linguistics, as well as in psycholinguistics. Let us review some investigation methods of in the field of discourse. T.Givon writes about the definiteness "if the speaker considers the reference as known, or accepts, he (the speaker) codes it as definiteness" (Givon, 1995). T.Givon claims that the reference can be restored by the help of some brain structures which exited in the brain of the speaker earlier. The most common spread brain structures are the following:

1. The current speech situation model (for example, I, you, this, one, here, now, etc.)

2. The permanent common lexical knowledge models (for example, the Sun, in the restaurant, the menu, etc.).

3. The episodic models of current texts. (For example, Jack..., He..., etc.)

T.Givon claims that "the majority of anaphoric reasons", or definiteness require to accept the last among these models (Givon, 1995). The main division about the reference is considered between the highest indicator of the succession (zero anaphora or unstressed pronoun), and the indicator of the other successions (inconsistency - a stressed pronoun (Givon, 1995).

The last models of T.Givon considers with the thought of E.Prince who describes the analysis of text units as Speaker-Known, or Listener-New and Discourse-Known, or Listener-New. The proper nouns enter the category of Listener-Known. Otherwise we have to use the indefinite expression instead of it. For example, My friend instead of Sandy Thompson. The status of the listener is not categoric, it is the indicator of definiteness typically (Givon, 1995). The pronouns show the status of the discourse as known, but it doesn't create the corresponding situation one by one. Most of the nominal elements are considered as Discourse-Known. T.Givon calls it as inconsistent reference.

E.Prins states that the mentioned division by T.Givon cannot be easily applied to the other categories of double difference units. In fact in this case Listener and Discourse can be counted as new ones. They may be accepted as Discourse-Known (Prince, 1992). Let us look over the following example using the word "door":

I passed by the Bastille and the door was painted purple.

The door of the Bastille was painted purple. 
The results of E.Prince are the hibrids of common lexical knowledge (the Bastille is a building, the buildings have doors) and the other episode in the text (the door is a door of something else in the text, the Bastille) in the three models introduced by T.Givon.

The third model of T.Givon, the episodic model of a current text, mostly is the anaphoric reference of the text. It explains the definiteness, and can be counted analogical of the thought of C.M.I.M.Mattiessen (Matthiessen, 1995) who considers the text as an important and real expression. In the brain description of the text the intersections should be supported correspondingly for giving guarantee of a fast connection with one another. It means that inside the brain text structure intersections should be connected with one another either systematically complete, or hierarchically adjoining, or can be connected with incomplete intersections (Matthiessen, 1995).

According to T.Givon these kinds of supporting process - the process of the connection of existing intersections with the new ones are completed by means of the anaphoric reference. Being against these processes C.M.I.M.Mattiessen states the importance of the role of the Theme. The Theme chooses the current developing point among all intersections in the text, and the last intersection must be added to this special intersection.

Having investigated the linguistic sources we think that the mutual connection between the definiteness and the Theme haven't been investigated empirically. But both T.Givon and E.Prince have stated some facts about the connection between the definiteness and the subject of a subordinate clause. Analyzing a short text (a finance appeal letter) E.Princy came to the conclusion that $38 \%$ of certain nominal clauses, and $10 \%$ of indefinite nominal clauses can be used in the role of the subject. Analysing the status of changeable listener, the status of discourse and the notion of definiteness he states that the role of the subject to the definiteness doesn't have any special importance, and the status of discourse explains "all changes". The units which were used earlier in discourse are used in the function of the subject (Prince, 1981). Inside the category of Discourse-Known the pronouns can be used in the role of the subject ( $81 \%$ of the pronouns are Subjects).

If we return to the subject of indefiniteness, we know that T.Givon also supported the notion of discourse from the point of view of cataphora. J.M.Sinclair called it as "supposition". T.Givon and the others investigated the length of the text units, and T.Givon called this parameter "the tolerance of the topic" (Givon, 1983). According to T.Givon the topic is considered as a discourse unit than being described as syntactical one. So, discourse and sentences can include some sentences. T.Givon also claims that "special grammatical signs" define the references, and these references "which are important, topical and persistent are shown in the next discourse, ... but the others which are non-topical stay unmarked (Givon, 1995).

T.Givon insists that indefinite references are one of the kinds of the cataphorical supporting. By the help of this supporting Speaker shows the New references which will be topical. He speaks about the connection of the grammatical subject and the indefinite article. $65 \%$ of the nominal elements which were marked by "this" is used in the function of the subject, $88 \%$ of the nominal elements which were marked by "a" are not subjects (Givon, 1995). This kind of use, the use of it as an indefinite cataphoric, of the pronoun "this" is not used in the official English writing style. As it is shown in the example:

Dear Abby, There is this guy I've been going with ... .

We think that, maybe, the writer used the cataphoric kind of supporting as T.Givon described. It means he used the limiting attributive clause with the combination of the indefinite article. Look over the example:

A guy I haven't seen in years.

Nevertheless, T.Givon claims that the cataphoric supporting can also be provided by means of subjectivity.

The definiteness and the indefiniteness are considered to grammaticize the discourse status in some cases. In this case the definiteness is characterized by Discourse-Known, and the indefiniteness by Discourse-New. It should be noted that discourse must refer to any certain unit. F.Danes calls this term as a Theme (Danes, 1974). We should like to draw your attention to the fact that he (F.Danes) doesn't accept the idea of a Theme coming at the beginning of a sentence. (But M.A.K.Halliday accepts it). For distinguishing the two mentioned notions we'll call the unit of Discourse-New which has indefinite position as D-Theme. The reference of D-Theme is shown in the earlier given sentence in the T-P (topic position) which is used systematically and straight-line thematic progression. Basing on T.Givon we can say that the systematically and straitht-line used T-Ps are maximal durable references, the formed T-Ps are followed by indefinite/systematic references. The unstressed pronouns are considered as systematically and straight-line TPs, but complete nominal units as Formed TPs. We must note that systematic and non-systematic D-Topics have the character of Discourse-Known and all nominal units which describe TPs are known in form. 
Therefore, neither T.Givon nor F.Danes can be made to accept the idea of M.A.KHalliday using D-Themes at the beginning of a sentence. But the only reason for checking this idea of M.A.K.Halliday is to measure the relative distribution of the definiteness and the indefiniteness at the beginning position; a) (Hallidaynian Theme) and indefinite position b) (HallidaynianRheme) which is meant as its continuation. Accepting Halliday's theory, we can see more definite signs in the Theme than in the Rheme. Although T.Givon doesn't refer to this fact, the fact doesn't make any problems in his investigation. E.Prins supports this idea in his investigation which describes the topic of definiteness. This idea encourages us to support the idea of using the pronouns in the Theme than in the Rheme. Nevertheless T.Givon's investigation about the indefiniteness is not observed in this hypothesis. On the other hand we can come to the conclusion that the indefinite article "a" is used in the function on non-subjectivity.

According to this hypothesis one can observe a lot of examples with "a" in the Theme, but it is necessary to stress that this point is related with the degree, and it also depends on the frequency of new topic units that enter the discourse. If the percentage indicator of this kind of intervention is lower, and the majority of Discourse-New references are not changed into Discourse-Topics in this case the number of the examples of "a" can be lower in the Theme than in the Rheme. We can suppose that the mentioned Themes can create the ground for similarity. Discourse-Known gives succession to the unit, but being new units Discourse can be used as subjects.

Now we would like to draw your attention to the above mentioned facts once more:

1. The indefinite indicators are used in less number in the Theme in comparison with the Rheme.

2. The definite indicators are observed in more number in the Theme than in the Rheme.

These procedures have the characters of some proof from most sides. Unlike E.Prins and T.Givon, the attempt to divide the nominal elements analyzing is not observed here. The complex expressions like some of the clauses that feminist groups stand for and proper nouns consisting of two elements for example, Winston Churchill can be found more than once in our research experiment. The usage of indefinite indicators gives the chance of pause to the speaker. Look over the example, the harder you worked, on the other hand, etc. Unlike this, the usage of the zero article hasn't been noted, and one of the elements of the indefiniteness hasn't been analyses. Technically $34 \%$ of elliptical sentences give exact information; in other words, some wrong "elliptical sentences" are observed in some words. This point doesn't separate the definite article from the demonstrative pronouns. It should be noted that one main point of this procedure is that in short period it covers the notion of a text relatively. It describes formal definiteness inside the text in the widest form, and never prefers the definiteness either in the Theme or in the Rheme. The defects in the exactness in the methods can be solved easily. For avoiding various results the mentioned and unmentioned Themes cover the text units mostly, they connect all subordinate clauses in themselves and can own different indefinite profile.

\section{Conclusion}

The investigation proves that the definite references are observed in the Theme more than in the Rheme, but it is not surprising that the definite and indefinite indicators can be used inside one text. The definite elements can also be observed in the same nominal elements unlike the Theme and the Rheme. The definite elements are observed more than the indefinite ones. In the contexts of mentioned and unmentioned Themes, the differences between the common indicators of definiteness attract special attention. In this case each subgroup refers to the different direction mentioned ones - to the direction of the Rheme, the unmentioned ones to the direction of the Theme. The articles, the pronouns refer to the Theme and are used in the Theme more than anyone supposes.

The comparison of mentioned and unmentioned Themes finds out many different tendencies. The indefinite articles are less used than the demonstarative pronouns in unmentioned context. The proper nouns should be used more than $17 \%$ in the Theme. The pronouns in the third persons he, she and they have some negative effects. It has also been proved that the mentioned Themes refer less to the model of Durable, Systematic and straight-line Progression than the unmentioned Themes.

\section{References}

Danes, F. (1974). Functional Sentence Perspective and the organization of the text. In Danes (Ed.), Papers on Functional Sentence Perspective. The Hague: Mouton. http://dx.doi.org/10.1515/9783111676524.106

Givon, T. (1983). Topic continuity in spoken English. In T. Givon (Ed.), Topic continuity in discourse: a quantitative cross-language study. Amsterdam: Benjamins. http://dx.doi.org/10.1075/tsl.3.08giv

Givon, T. (1995). Functionalism and grammar. Amsterdam: Benjamins. http://dx.doi.org/10.1075/z.74 
Halliday, M. A. K. (1967). Notes on transitivity and theme in English, Parts 1 and 2. Journal of Linguistics, 3(1), 37-81. http://dx.doi.org/10.1017/S0022226700012949

Johansson, S., Atwell, E., Garside, R., \& Leech, G. (1986). The tagged LOB Corpus: User's Guide. ICAME, The Norwegian Computing Centre for the Humanities, Bergen University, Norway.

Martin, J. R. (1995). More than what the message is about: English Theme. In M. Ghadessy (Ed.), Thematic Development in English Texts. London: Pinter.

Matthiessen, C. M. I. M. (1995). THEME as an enabling resource in ideational "knowledge" construction. In Ghadessy, M. (Ed.), Thematic development in English Texts. London and New York: Pinter.

Prince, E. (1981). Toward a taxtonomy of given-new information. In P. Cole (Ed.), Radical pragmatics. New York: Academic Press.

Prince, E. (1992). The ZPG letter: subjects, definiteness, and information status. In W. C. Mann \& S. A. Thompson (Eds.), Discourse description: divers linguistic analyses of a fund-raising text. http://dx.doi.org/10.1075/pbns.16.12pri

Sinclair, J. M. (1994). Trust the text. In R. M. Coulthard (Ed.), Advances in written text analyses. London: Routledge.

\section{Copyrights}

Copyright for this article is retained by the author(s), with first publication rights granted to the journal.

This is an open-access article distributed under the terms and conditions of the Creative Commons Attribution license (http://creativecommons.org/licenses/by/3.0/). 